\title{
El siglo XX, el despertar de la narrativa femenina El bildungsroman femenino en la novelística de Carmen Laforet
}

\author{
Dra. Laila A. Awadallah* \\ laila_a2001@hotmail.com
}

\section{Resumen}

El trabajo se titula "El siglo XX, el despertar de la narrativa femenina, El bildungsroman femenino en la novelística de Carmen Laforet". El trabajo estudia los albores de la novelística femenina en España durante la primera mitad del siglo $\mathrm{XX}$ y sus figuras más representativas enfocando en Carmen Laforet, pionera de la literatura femenina española. El presente estudio aborda el tema del buildungsroman en las novelas de Carmen Laforet, quien ha recorrido a esta técnica narrativa a lo largo de sus dos primeras obras. De costumbre la técnica del buildungsroman se utiliza en una novela para contar el crecimiento y el desarrollo ocurridos en el carácter del protagonista. La aportación de Laforet se queda en usar esa técnica para describir su protagonista, tanto físicamente como moralmente en las dos obras como se fueran una sola novela dividida en dos partes. La primera lectura de las dos novelas dan la impresión que son dos obras separadas, sin embargo una lectura atenta abre otros horizontes y deja al lector pensar que forman una sola obra de la misma protagonista con todos sus detalles idénticos de aspecto y condiciones de vida, contados en orden retrospectivo, es decir la segunda obra se ocupa por darnos informaciones sobre los

* Profesora titular de Lengua y Literatura hispánica- Facultad de Lenguas (Al-Alsun)- Universidad de Ain Shams.

(El siglo XX, el despertar de la narrativa femenina...) Dr. Laila Awadallah 
primeros años de la protagonista, mientras la segunda narra su historia tras de crecer y convertirse en una joven.

Palabras clave: Carmen Laforet, Siglo XX, Novelística femenina, El bildungsroman .

\section{Introducción:}

El punto de partida de nuestro trabajo, que pretendemos que sea el primero en una serie de ensayos o artículos que tratan este periodo, lo fundamento en cuanto al inicio y el auge de la literatura española realizada a través de la pluma de mujeres escritoras, sobre todo, las pioneras que abrieron el camino y facilitaron el acceso al ámbito de las letras a otras escritoras. A partir de la década de los 80 del siglo XX surgen en el campo literario muchos nombres de grandes escritoras y novelistas que no habrían sacado su producción a la luz sin los esfuerzos de literatas reconocidas precursoras como Carmen Martín Gaite, Ana María Matute o Carmen Laforet, entre otras, que ya publicaban en la segunda mitad de los años $40^{\mathrm{a}}$.

Para comenzar, hemos seleccionado a la escritora Carmen Laforet, (Barcelona, 6 de septiembre de 1921 - Majadahonda, 28 de febrero de 2004), y su primera novela, Nada, publicada en 1945, por varias razones: por un lado, es la primera novela de la joven escritora Carmen Laforet, considerada una gran pionera entre las escritoras de posguerra; también por ser ésta la obra ganadora de la primera edición del prestigioso Premio Nadal, en

(El siglo XX, el despertar de la narrativa femenina...) Dr. Laila Awadallah 
1944; por otro lado, y sobre todo, por ser considerado este texto que seguidamente analizaré, el primer bildungsroman ${ }^{1}$ femenino en el siglo XX. El valor de esta novela no sólo se obtiene por el premio, sino también por abrir un nuevo capítulo en la historia de la Literatura escrita por mujeres. A partir de esta fecha, las mujeres cosechan una gran variedad de premios importantes. El mismo premio Nadal fue otorgado a mujeres cuatro veces durante los años posteriores. Laforet, por ejemplo, volvió a ser galardonada con el Premio Nacional de Literatura, en 1956, y el Premio Menorca de Novela, en el año 1955. La novelística femenina deja de ser marginal para pasar a formar parte inseparable del mundo literario en España.

Es la mejor obra de Laforet según muchos críticos, y esto lo veremos a lo largo del presente estudio. Cabe destacar que los críticos abordaron la novela Nada desde muchos enfoques, sobre todo el punto de vista temático, ya que la obra es rica en temas que se consideraban novedosos en la década de los años 40, una vez acabada la guerra civil española.

Adentrándonos en la novela y su personaje principal, destacamos los trazos generales de la rebelde Andrea, una chica joven que está a punto de cumplir los veinte años de edad. Su personalidad y maneras de hacer fueron bastante chocantes para la época de los cuarenta del silgo XX, que se sumergía en una dura posguerra donde el papel femenino estaba supeditado a la familia, a la casa, y al trabajo doméstico o en la fábrica. Las ocupaciones 
de las mujeres estaban muy delimitadas, con un bajo techo de cristal contra el cual no podía luchar ni elevarse en trabajo de más alto nivel de formación y de educación. Por ello el papel de este personaje enmarcado dentro de la crítica social de la política en España tras la guerra civil española que justo acababa en 1939, simbolizado en la casa de la familia de Andrea, en Barcelona.

Digno es decir que en el momento de seleccionar Nada, de Laforet, para ser ejemplo de un bildungsroman femenino, nos sorprendió enormemente que no pudiera estudiar la obra que estamos exponiendo sin mencionar la segunda obra de la autora. Una obra madura que se publica una década más tarde, en 1952, La isla y los demonios, ambientada en la isla de Gran Canaria. Las dos obras, junto a su tercera novela, La mujer nueva, 1955, que trata la historia de una mujer madura de mediana edad. Esta trilogía constituye y describe los requiebros de las tres etapas vitales de la novelista y de la condición femenina. No obstante, lo que nos interesa en el presente estudio son estas dos primeras obras, que relacionaremos y analizaremos para encuadrar un paralelismo entre estas dos visiones del hecho femenino como protagonista de un relato fantástico novelado y se relaciona con la propia vida de la escritora, la dualidad entre escritora y personaje.

Estudiar una novela desde el punto de vista de la construcción del estilo bildungsroman no es nada nuevo, ya que existen anteriores trabajos que han estudiado Nada desde este enfoque. Por ejemplo: Mujeres en proceso de construcción, de 
Caroll Buitrago-Long, y Carlos Javier Vadillo Buenfil, en su tesis doctoral: El bildungsroman en las narradoras españolas de posguerra: 1940-1960. Sin embargo, el objetivo que pretendemos plantear es si es posible que Carmen Laforet nos ofrece la doble historia de un bildungsroman dividido en dos obras que trata dos periodos de la vida de unas mujeres, con su peculiar marco social y geográfico. Este enfoque reconozco que es único, un fenómeno en solitario dentro de la narrativa española en este siglo XX marcado por los cambios geopolíticos, económicos y sociales.

Este trabajo se estructura bajo el método analítico descriptivo. Sería necesario analizar los elementos componentes de ambas novelas, Nada y La isla de los demonios, con el fin de comprobar la veracidad de una auténtica semejanza entre la figura de la protagonista, así como de un cierto seguimiento en la descripción, hasta el punto de llegar a un idéntico personaje. ¿Será Marta la misma Andrea en los años de la primera adolescencia? ¿Podrá Andrea realizar en Nada los sueños de Marta al trasladarse de su ciudad natal a la gran ciudad, sea Barcelona o Madrid? ¿Existe o no una semejanza entre el entorno familiar que rodea a la protagonista en ambas obras? A modo de conclusión: ¿Podría considerarse que La isla de los demonios forma, de modo reversible, una continuación de Nada, y que las dos juntas formen una única novela dividida en dos partes? Esta es la cuestión principal que toma fuerza en la presente hipótesis que pasamos a 
desarrollar seguidamente bajo este método analítico de los personajes.

\section{Los albores de la narrativa femenina:}

A lo largo de la Historia Antigua y Moderna, bien entrado el Renacimiento y el descubrimiento de la imprenta, hasta la época Contemporánea, existían modestos y pocos ejemplos de mujeres que participasen en la vida literaria, siendo la mujer la principal transmisora de la tradición oral y cultural humana a través de métodos pedagógicos muy básicos para entretener y cultivar a su descendencia, con los cuentos que guardaba en la memoria, cuentos y narraciones orales que se transmitían en el ámbito íntimo familiar y del grupo cercano o familia extensa. Pocas mujeres accedían al mundo de las Letras, incluso familiarizarse con la lectura y la escritura era un privilegio para ellas. Para las chicas bien se reservaba instruirla en algún instrumento musical, las labores de costura, tejido y bordado y la repostería. Sin embargo, las que ascendían a publicar sus escritos, gran parte lo hacía a través de pseudónimos para ocultar su identidad y posición social. De esta manera se ahorraban los obstáculos de la crítica masculina aferrada a unas costumbres de jerarquía en la que los roles podían estar en cuestión. Muchas de ellas utilizaban nombres masculinos para no ser descubiertas. Por ello, estos escasos casos de producción literaria femenina que han podido salir a la luz constituyen un legado de verdaderas pioneras

(El siglo XX, el despertar de la narrativa femenina...) Dr. Laila Awadallah 
que dieron un salto en la dirección correcta hacia la inteligencia y el conocimiento. La tradición literaria de algunas mujeres ha marcado las vidas de generaciones posteriores de mujeres que estudian y llevan a la práctica sus conocimientos a través de sus textos y su sabiduría.

Desde la prehistoria hasta la época de los primeros cristianos hace dos mil años hay escasos casos de mujeres escritoras, el caso de Safo de Lesbos es una de las excepciones, ya que, como hemos mencionado, la mujer se dedicaba a tareas domésticas, a la crianza y a la educación de los hijos. La historia de la literatura española o hispanoamericana menciona a pocos nombres de mujeres famosas en el campo literario, una gran parte de ellas fueron conocidas como poetisas, sobre todo en la poesía mística y religiosa como Teresa de Jesús (1515-1582) y Sor Juana Inés de la Cruz (1648-1695), debido a que en la época del Antiguo Régimen la iglesia era uno de los reductos de poder en relación al conocimiento y educación de las Letras y las Ciencias. Tenemos que dar un gran salto en el tiempo, después del siglo de las Luces y la Ilustración, que destaca por los movimientos intelectuales y culturales sobre todo europeos, el siglo XVIII, para pasar al siglo XIX, durante el cual ilustres nombres de participantes femeninas, muchas veces bajo seudónimos diferentes, comienzan a dar a publicar sus textos desde una posición que les permitía compaginar la vida doméstica con la literaria. Por ejemplo, casos como Cecilia Böhel de Faber (Fernán 
Caballero), Mary Ann Evans (George Eliot), Amantine Dupin (George Sand), o la gallega Gertrudis Gómez de Avellaneda (Emilia Pardo Bazán) representan el prototipo de escritora con una posición social elevada miembro de una familia burguesa donde correspondían a la vez con el papel de esposas y madres.

La mujer española no lo tuvo fácil hasta avanzado el siglo XX para dedicarse al ejercicio de la Literatura debido a los acontecimientos sociopolíticos, el acceso de las mujeres al mundo del trabajo y de una industria incipiente que debía cubrir y compaginar con las tareas del hogar porque la mayoría de hombres estaban en alguna de las guerras que asolan la primera mitad del siglo XX. No obstante, los vientos de la Guerra Civil española soplaron fuerte, dejando grandes secuelas generacionales, y dieron vuelta atrás a todos estos derechos ganados por parte de la mujer como por ejemplo el derecho al divorcio. El impacto de la guerra fue rotundo, sin embargo, algunas mujeres bravas pudieron sacar la cabeza por debajo de los escombros para lanzar sus gritos pidiendo libertad e igualdad. Será en la segunda mitad de siglo XX que se experimentará un auge en las publicaciones femeninas. Los derechos que comienzan a gozar las mujeres españolas en el período desde finales del siglo XIX hasta finales del XX, y a partir de 1976 con la democracia, suponen un salto de gigante. Sobre todo, destacar los derechos redactados en la Constitución de la II República con el voto femenino, en ese derecho de sufragio que hoy día en el 
siglo XXI parece tan indiscutible y natural, supuso un paso adelante en todos los sectores de la vida humana, no únicamente para las mujeres..., el acceso a la Universidad, los viajes, el mundo del trabajo, la tecnología, las ciencias, la investigación o las publicaciones, etc., han tenido un rol importante en el florecimiento de la Literatura escrita por mujeres a partir de los años cuarenta del siglo XX en adelante en España, y en el mundo en general, ya que la globalización y el acceso a Internet, se han constituido en conexiones de conocimiento, enseñanza y aprendizaje, que parece no tener límites por el momento. Todo está conectado, el mundo se conecta las veinticuatro horas del día y se fomenta el teletrabajo en los momentos actuales partiendo de la base de que lo que realmente se fomenta es la confianza en el potencial humano y sus conocimientos técnicos y culturales, prescindiendo de otras particularidades por razón de sexo, ideología o raza, religión o costumbres culturales, o situación geográfica.

\section{Proyección de la vida de Carmen Laforet en Nada:}

Carmen Laforet Díaz, novelista española que cosechará tanto novela como cuento y relato corto, nacida en Barcelona en 1921, primogénita de una familia acomodada de la burguesía española. Su familia se traslada a las islas Canarias en 1923 y Carmen pasa allí el resto de su infancia y una buena parte de su adolescencia. Canarias, que ha dejado sus huellas en el carácter de 
la joven escritora, iba a ser el escenario de su segunda novela, $L a$ isla y los demonios. Después de perder a su madre, y el enlace de su padre con otra mujer, acabado el Bachillerato y con dieciocho años de edad decide dejar la casa de sus años de crecimiento para volver a su ciudad natal, Barcelona. En esta localidad catalana es donde van a transcurrir los sucesos de su primera obra, Nada, novela de gran realismo existencial con la que gana la primera edición del Premio Nadal, otorgado por Ediciones Destino, a los veintitrés años de edad. Esta obra se ha convertido en una de las más importantes novelas europeas de la época de la posguerra, así como una de las obras más leídas, reeditadas y traducidas en la historia de la Literatura española y universal. La fama de Nada se iguala al Quijote, o a La familia de Pascual Duarte, en el número de ventas, de ejemplares publicados, y de traducciones. La insólita aportación que introdujo Laforet es básicamente en relación a la temática de la obra. Sin olvidar que el contexto que la envuelve está dentro de un ambiente intelectual, mayormente machista en un país militarizado y sin libertad de expresión, donde el género literario más predominante para las escritoras era la novela rosa que presentaba una visión del mundo apartada de la realidad, una realidad dulce y propicia principalmente para gozar del amor de pareja. Con la aparición de Nada, una novela que ofrece una narrativa diferente, incorpora el ejemplo personal de la mujer que también puede ser creativa y productiva, e igualarse en este rol al género masculino.

(El siglo XX, el despertar de la narrativa femenina...) Dr. Laila Awadallah 
La sensibilidad de Carmen Laforet en captar con detalle todo lo que rodea y su capacidad de transmitirlo en un ambiente vivido, lleva a muchos críticos a dudar si era una novela o era más de su autobiografía, dada la gran dosis de veracidad que engloba todas las acciones de la novela.

Carmen Laforet optó por matricularse en la Facultad de Filosofía y Letras al llegar de joven a la ciudad Condal. Pero la estancia de la joven Laforet en Barcelona no fue muy agradable, por tal razón decidió trasladarse a Madrid para empezar una nueva carrera universitaria, de Derecho, ambas no acabadas. Sin embargo, Carmen Laforet se dedicó a escribir su primera obra literaria Nada, que fue seguida de otras novelas y colecciones de cuentos como La isla y los demonios (1952), La mujer nueva (1955), Un matrimonio (1956), además de recibir más premios destacados como el Premio Fastenrath de la Real Academia Española (1948), el Premio Nacional de Literatura (1956) y el Premio Menorca de Novela, de 1955.

A pesar de la gran concordancia entre el transcurso de la vida propia de Carmen Laforet y los acontecimientos que rodean a Andrea, protagonista de Nada, su primera novela, o Marta Camino, de su obra La isla y los demonios, e incluso de Paulina Goya, de La mujer nueva, sin embargo cada una de sus protagonistas lleva algo de su vida, de su carácter, de su ánima o alma (porque volvió a reconvertirse al catolicismo). Hasta tal punto se complementan que las tres novelas podrían formar una 
trilogía. Y esta triple visión de las etapas vitales femeninas revela algunos aspectos tanto de la historia real de Carmen como de la sociedad española en esta época tenebrosa de posguerra española y de la II Guerra Mundial. El caso de Andrea se asemeja más aún con su creadora, a pesar de la negación de Carmen Laforet a la idea de que sus libros fueran autobiográficos, sobre todo Nada.

"Hasta aquí la historia de una muchacha de veintidós años. De esa época en adelante sabréis todo aquello que tenga conexión con mis libros en las pequeñas notas que he escrito al comenzar los distintos periodos de mi obra. Por estas anotaciones y por los fragmentos de mis libros veréis que, si mis novelas están hechas de mi propia sustancia y reflejan ese mundo que -según os explicaba antes- soy yo, en ninguna de ellas, sin embargo, he querido retratarme" 2 .

Efectivamente, a pesar de esta clara negación por parte de Carmen Laforet (no querer retratarse), sin embargo su vida y la de Andrea se parecen, en muchos momentos de la obra son casi idénticas. Las dos vinieron desde Las Canarias a Barcelona para estudiar en la Universidad. Carmen salió de casa huyendo de los malos tratos de su madrastra. Ella misma lo describe con estas palabras: "... a pesar de todas mis resistencias a creer en los cuentos de hadas, me confirmó su veracidad, comportándose como las madrastras de esos cuentos. De ella aprendí que la fantasía siempre es pobre comparada con la realidad"3. En tal 
caso, se relaciona con el personaje de Andrea, en tanto en cuanto ésta se cansaba de los conflictos y peleas con su prima, quien la cuida tras la muerte de sus padres. Ambas empezaron una carrera de Filosofía y Letras, no acabada nunca tanto por parte de Carmen, como por Andrea. Las dos chicas son aficionadas a la lectura: llega Andrea cargada con una maleta muy pesada llena de libros; la casa de abuelos donde vive durante su estancia en Barcelona está ubicada en la calle de Aribau. Como el caso del final de la novela con el traslado de Andrea a Madrid para empezar una nueva vida con la familia de su amiga Ena. En la vida real, Carmen Laforet deja la casa de sus abuelos para ir a buscar nuevos horizontes en la capital, allí empezó a escribir Nada, fruto de esos tres años que pasó en la casa de los abuelos. Esto es lo que llevó a Teresa Amiguet a escribir: " $Y$ es que, aunque Carmen defendió que su novela no era autobiográfica nadie le creyó y él menos que nadie, (refiriéndose a su esposo el periodista y crítico literario Manuel Cerezales) que le insistió durante toda su relación en que evitara la autobiografía"4.

Algunos críticos posteriores hicieron una comparación entre Nada y la legendaria novela de Emily Brontë, Cumbres borrascosas, o, también, comparada en el éxito obtenido con la novela Cien años de soledad (1967), del colombiano Premio Nobel de Literatura, Gabriel García Márquez ${ }^{5}$. De cualquier modo, Nada ha reservado su lugar entre las obras maestras de la Literatura española, como una de las obras más traducidas de 
todos los tiempos de una escritora que supo brillar con sus textos. Como venimos mencionando, en el contexto histórico en el que vive Carmen, como autora y como esposa, no resultaría nada fácil aceptar ese 'exhibicionismo autobiográfico'. Aceptarlo públicamente, contar la vida de una mujer, no resultaba decoroso en la alta sociedad. La madre de familia, la joven adolescente o la niña y sus entornos íntimos, lo femenino siempre debía quedar oculto y selectivo para la familia. ¿Quizás por este motivo Laforet rechaze la idea de reflejar su vida en el texto?

\section{El bildungsroman o la novela de formación:}

El bildungsroman; la novela de formación, de aprendizaje o de educación es un estilo de novela en el que su protagonista sufre cambios de pensamiento y actitud a medida que crece y llega a la edad adulta. "El término en alemán, creado por el profesor Karl Von Morgenstern en 1810 para un curso en la universidad, es más restringido a lo que se le ha traducido: Bildung corresponde al período de formación después de la enseñanza primaria y Roman (novela), se utiliza para clasificar a las novelas que se centran en el crecimiento psicológico y moral de un personaje desde su adolescencia hasta su adultez". $\mathrm{Al}$ aplicar esta definición a las obras de Carmen Laforet vamos a ver que sus tres primeras novelas siguen ese estilo o esta clase estética de novelas. A parte de la construcción de la novela, existen ciertos temas tan abundantes de este tipo que describen la búsqueda de la 
identidad, la migración, la rebeldía, entre otros estados de la identidad. Podemos añadir un tema más en la escritura de Laforet y sus coetáneas, la orfandad, que resulta muy evidente por la cercanía de situaciones en que los padres mueren a causa de las guerras y la falta de alimentos y protección social, o bien no pueden hacerse cargo de los hijos pequeños. Este es el caso de Carmen, pero en otras circunstancias, es la pérdida de su madre, a la edad de trece años, la que ha dejado sus profundas e intachables huellas en el carácter y en la formación literaria de la escritora.

La novela de formación femenina adopta formas diversas, pero la más abundante es aquella que relata el paso de la adolescencia de la protagonista a su plenitud como mujer, como es el caso de Andrea en Nada, y Marta en La isla y los demonios. Sus heroínas se destacan también por su rebeldía y su profundo anhelo por independizarse.

“...es significativo que muchas de estas autoras investigan en sus primeras ficciones ese período de tránsito que lleva a la niñez a la vida adulta con un personaje de similares características: una adolescente solitaria y sensible, desligada física o espiritualmente de su familia y que se rebela de forma más o menos brusca ante las normas sociales que considera hipócrita e injustas. La novela femenina de posguerra estableció un nuevo tipo de personaje, que Martín Gaite denominó la chica rara. La novelista consideró que Andrea, la protagonista de Nada

(El siglo XX, el despertar de la narrativa femenina...) Dr. Laila Awadallah 
(1944), era el precedente literario de este nuevo personaje que suponía una abierta ruptura con el comportamiento femenino habitual en otras novelas anteriores escritas por mujeres" $"$

\section{Nada, primer bildungsroman femenino en la España de posguerra:}

Se puede clasificar a Nada como una obra de denuncia social: "Aunque con una mirada más profunda se puede ver la crítica social y política de la situación de España en ese momento a través de la división de la familia y la pobreza que invadió los hogares de clase media catalana después de la Guerra Civil", o quizás pertenece a la literatura de entretenimiento con pocos rasgos esencialistas, existe una lucha entre los valores dominantes en la sociedad y la protagonista, símbolo de una generación entera. Carmen López opina lo siguiente:

"Durante muchísimos años -aún hoy hay quienes lo hacen- se ha calificado esta obra prima de Laforet como una 'novela de postguerra'. A nuestro parecer por lo único que se la puede calificar así es por su fecha de aparición, pues carece de una forma evidente de tintes sociales. Lo que Carmen Laforet pretendió no fue convertir su novela en una prolongación de las consecuencias de la Guerra Civil en la España de los años 40. Entendemos que la autora, dado el momento histórico, hace constar que la 
guerra estuvo ahí y que ya había terminado; pero lo hizo brevemente y a su debido tiempo -al comienzo de la novela-. A partir del encuadre geográfico-cronológico todo se sucede en torno a las relaciones familiares y personales dejando al margen las consecuencias sociales de la guerra9."

No obstante, no compartimos con la autora estas ideas sobre la novela de Carmen Laforet, ya que opinamos que Nada ofrece grandes declaraciones sobre la penuria en que vivió la sociedad española tras la Guerra Civil, sobre todo bajo la estricta censura impuesta por el régimen franquista. Laforet refiere a la gran hambruna que sufrió la familia de Andrea y la escasez de todos los alimentos básicos en un tiempo que sólo se podían conseguir mediante el uso de cartillas de subsidio o llamadas también 'cartillas de racionamiento'.

Mientras una buena parte de los críticos se inclinan a la idea de que Nada es una obra autobiográfica donde narra Carmen Laforet una serie de sucesos reales ocurridos en su vida, otros optan por la creatividad innata de Laforet que logró convencer al público con la veracidad de unos hechos imaginativos. "Las novelas de Carmen Laforet no son diarios de la autora, por lo que no debemos entender los sucesos narrativos como los hechos que a ella le acaecieron. Eso no solo sería una gran equivocación, sino también una gran injusticia, porque iría en detrimento de la capacidad fabuladora de la novelista"10.

(El siglo XX, el despertar de la narrativa femenina...) Dr. Laila Awadallah 


\section{Concepto y estilo:}

Para comenzar hay que hacer hincapié sobre el término al que hacemos referencia de 'Literatura femenina'. Este tipo de literatura será la escrita por mujeres, o la escrita para mujeres, o sea, aquella protagonizada por una o varias mujeres. Un tema discutido por parte de muchos críticos como Carmen Martín Gaite, en su libro Desde la ventana. Enfoque femenino de la literatura española, y también, el libro La mujer y la Literatura: escritoras, público y crítica en la España actual, de Laura Freixas. De ahí surge el punto de partida de cualquier obra literaria, ya que Nada, de Carmen Laforet, rompió con todos los moldes literarios existentes en la sociedad española de antes de Guerra Civil, que redactaban el género de novela rosa exclusivamente para mujeres lectoras o escritoras, como único ámbito de paso literario, único género literario cultivado por y para mujeres.

Ser mujer durante la primera mitad del siglo $\mathrm{XX}$ significaba vivir subordinada al varón, tener la identidad amputada y quedarse reclusa en el hogar. Por lo cual, Nada formaba un choque contra las normas morales franquistas dominantes en la sociedad española de posguerra. Cuando Laforet escribe esta historia no resultaba fácil publicar un tema tan claro de cuestionamiento de los valores. Podemos decir que pasar la censura a veces era cuestión de suerte o de picardía, cómo explicar algo importante sin que se note demasiado. Sin embargo,

(El siglo XX, el despertar de la narrativa femenina...) Dr. Laila Awadallah 
lo que Carmen Laforet pretendió era trazar una imagen de una sociedad devastada, por un lado, económicamente por la guerra, y, por otro, moralmente. Muchos jóvenes sienten rebeldía contra todas las creencias existentes en la dictadura de mediados del siglo $\mathrm{XX}$, con una voluntad clara de cambiar todo que los rodea. Pero el país está dividido: "las dos Españas". Los persistentes intentos de Andrea para cambiar la vida de sus parientes con los cuales comparte la casa en la calle de Aribau fracasaron todos, sin embargo, logró transformarse a nivel personal, abriéndose de par en par las puertas hacia una nueva vida.

Laforet se considera la primera escritora perteneciente a la corriente literaria llamada "tremendismo"11, que surgió tras la guerra para describir los horrores y el impacto que dejó en el estado de ánimo y modo de vida de todo el pueblo español. El movimiento tremendista se caracteriza por un estilo realista con algunas características propias y con aspectos ciertamente especiales. En el caso concreto de Laforet, algunos estudios la califican como una escritora neorrealista ${ }^{12}$. Consecuentemente con este estilo, muchos autores explican el tremendismo como un tipo de realismo existencial en el cual se acentúan los aspectos más básicamente vitales de los humores extremos y su plasmación en la novelística y la Literatura en general, dando lugar también, por otro lado, al realismo social. Desde el punto de vista filosófico, el tremendismo es determinista, y con grandes rasgos de fatalidad y pesimismo, con un punto de vista negativo sobre la 
vida humana, dado que los conflictos bélicos, la pobreza y la necesidad hacen que esta época de la primera mitad del siglo XX tenga los componentes necesarios para que este tipo de lecturas fueran las que inspiran y motivan tanto a lectores como a escritores. Estas obras rompen con el canon y se dedican a describir al detalle incluso aquello repugnante o desconcertante, o doloroso, bajo esa crítica social o existencial de la vida que les rodea en su contexto. Carmen Martín Gaite y Carmen Laforet se apuntan a esta corriente tarde y tomarán un estilo propio, ya que el tremendismo aparece con fuerza en la generación del 36, y, según Ortega y Gasset, el tremendismo se entrelaza con la picaresca española como el ejemplo de la precursora Celestina, es decir, surge en los años cuarenta y tienen un auge tremendo enraizado en la tradición realista española, pero en los años cincuenta se extingue. Otras autoras comenzarán a escribir bajo este estilo, por ejemplo, las escritoras Susana March, Rosa María Cajal, o Eulalia Gavarriato ${ }^{13}$. Otra pionera, Martín Gaite, en su obra tremendista Los Abel, se centra en una crítica al sistema patriarcal y el subdesarrollo de la sociedad capitalista e industrial de posguerra. Y en Nada, Laforet no podía ser menos, nos enfrentamos a esa visión negativa del contexto de la época, enmarcado en los rasgos de ingenuidad de la protagonista de la novela, una joven que busca su lugar en una sociedad convulsa y que quiere poner el acento en la libertad de su juventud, en su búsqueda de lo nuevo para dejar atrás un costumbrismo que en la

(El siglo XX, el despertar de la narrativa femenina...) Dr. Laila Awadallah 
época no deja de fundamentarse en la gran necesidad de romper para que la suerte de un giro a la vida. El dilema entre tradición y vanguardia, entre lo privado y lo público, la comunidad y el individualismo.

\section{Ausencia de la madre:}

Otra característica importante en las novelas de formación femenina de posguerra consiste en la ausencia de la madre; o sea a causa de la muerte, como la madre de Andrea, o a causa de su discapacidad. Este es el caso de la madre de Marta. El símbolo de la madre ausente en todas las novelas de formación femenina es muy significativo, ya que la madre representa la guía orientadora y transmisora de valores, según el concepto de la maternidad de la época. Esa carencia, por tanto, tiene como resultado que las adolescentes no han aprendido comportamientos $\mathrm{y}$ referentes marcados por la jerarquía materna dentro de la familia, ejemplo de sus hijos. Y, sobre todo, esta falta las marca porque la sociedad espera que una madre les haya enseñado. Es un doble castigo, por decirlo así, social y personal.

Laforet escribió otras cuatro novelas en las cuales intentaba siempre buscar nuevos modos para promover un mensaje femenino. No es nuevo decir que Nada se puede clasificar como el primer bildungsroman femenino tras la Guerra Civil. La novela arrasa en todas las librerías hasta llegar a reimprimirse tres veces en el mismo año. La obra narra los sucesos de la vida de una

(El siglo XX, el despertar de la narrativa femenina...) Dr. Laila Awadallah 
adolescente a lo largo de un año de su estancia en la casa familiar, tema que hizo furor tanto en los círculos académicos como en la calle. Y como fue tan bien recibido en los círculos culturales, la animó a repetir la prueba unos años más tarde. Es en 1952 cuando vio la luz su segunda novela: La isla y los demonios, que cuenta una gran parte de su infancia y adolescencia en las islas Canarias. Y el título no es una casualidad, para muchos investigadores y personas comunes la isla significa el ideal utópico de la vida feliz, mientras que para Laforet es una distopía, la negación de toda esperanza de felicidad, de ahí esos demonios, y esos desastres. Remontándonos unos siglos atrás en Londres, Tomás Moro (1478-1535) escribe Del estado ideal de una república en la isla de Utopía, ya da nombre a esa isla ideal y fantástica. La idea de isla en Laforet representa un despertar interior y exterior, de lo diminuto y mínimo a la idea existencial más potente y profunda. De ahí se sustrae esa fijación descriptiva hacia la opresión de la familia que también representa una isla en sentido figurado.

\section{Emancipación de Andrea:}

En esta obra, estamos ante una novela que nos expone dos mundos diferentes: El mundo de Andrea, que protagoniza persistentes intentos de emancipación. Y, por otro lado, el mundo de la casa de la calle de Aribau. Esta casa está llena de personajes oscuros, que, por supuesto, cada uno de ellos ha dejado sus

(El siglo XX, el despertar de la narrativa femenina...) Dr. Laila Awadallah 
huellas intachables sobre la formación del carácter de la nueva Andrea, según el análisis de Miguel Ángel García Guerra:

"El resto de los personajes que aparecen en la novela representa un mundo gris que descubre la cara más desagradable y oscura del ser humano. Estos personajes protagonizan un buen número de pasajes sombríos que dejan en el lector una sensación incomoda, al mismo tiempo que contribuyen a la evolución que Andrea debe emprender para afianzar su personalidad si no quiere enloquecer" 14 .

La segunda parte de la narración aborda la vida de Andrea tras ser liberada de la vigilancia intensiva de la tía Angustias. Con la escapada, la chica empieza a disfrutar el deleite de una sensación dulce, de su libertad. El conflicto generacional se ve claramente en esta fase de la vida de Andrea. La joven protagonista explica sus sensaciones al irse de casa: "De que no iba a obedecer más, después de aquellos días de completa libertad que había gozado en su ausencia" 15 . A pesar de que su tía tenía más o menos la edad de su difunta madre, sin embargo las dos mujeres no se entendían de ningún modo. Angustias adoptaba todas las creencias dominantes de la época medieval, es decir, una mentalidad conservadora y retrógrada sobre el papel designado a la mujer y sus deberes hacia su casa y su familia, sobre todo los asuntos relacionados con el cónyuge. Quedarse soltera era de lo más desagradable para una mujer que quisiera 
avanzar y ser reconocida en la sociedad española. A las jóvenes que llegaban a una cierta edad sin casarse, se les decía que iban a quedarse para vestir santos. Es una expresión muy típica y muy usada en la época hasta la actualidad. Eso quería decir que no iban a conocer hombre y sólo se las iba a ver en la iglesia. Decir esta expresión era casi una amenaza o una condena para estas mujeres. Una jovencita sólo tenía dos opciones: Echarse un novio o dedicarse al servicio religioso y convertirse en una monja. Pero Andrea pertenece a una nueva generación con otros ideales más elevados. Se crio y fue educada durante los años de la Segunda República con todas las ideas del momento sobre las libertades, el voto femenino y la emancipación de la mujer, y su indispensable participación en la vida pública.

Mientras la tercera parte nos cuenta los verdaderos cambios ocurridos en el carácter de Andrea, su liberación ya no es una mera sensación, y de hecho se convierte en realidad. La chica adolescente se transforma de una persona pasiva a otra activa y diferente. Sabe perfectamente lo que quiere y decide su futuro a su gusto. Es en esta última parte donde empieza a controlar bien su vida. Andrea arguye que su único camino de salvación será tanto por la educación universitaria como por la independencia económica. A diferencia de las novelas rosas, género literario muy de moda por las escritoras españolas antes de la aparición de esta novela que analizamos, la protagonista aquí no busca un romance, un enlace amoroso, al contrario, busca construir su 
propia identidad mediante la educación y el trabajo. El personaje de Andrea busca su propio Universo personalísimo.

Otro aspecto destacado en el carácter de Andrea es su discreción. La adolescente es el miembro más joven de la familia, a pesar de su corta edad, pronto se convirtió en la confidente de toda la familia, desde la abuela pasando por los tíos, y terminando por Gloria, a parte de la madre de su íntima amiga Ena. Andrea tiene la habilidad de pasar las horas escuchando las confesiones de todas las personas que la rodean, no obstante, ella misma carece de confianza en sí misma y en los demás. Andrea se siente marginada, tanto dentro de su familia por las duras circunstancias que la rodean, como en la Universidad, dado su aspecto pobre, sus zapatos gastados y su extrema penuria: "Las referencias constantes a la ropa de Andrea, el abrigo viejo, los zapatos con agujero en las suelas y su hambre contrastan drásticamente con las escenas de riqueza en los encuentros intelectuales en casa de Ena y la fiesta pomposa en casa de Pons ${ }^{16 " .}$. Andrea se sentía siempre avergonzada por su apariencia, lo que profundizó su sentido de soledad y dejó marcas inolvidables en la formación de su carácter.

\section{Andrea, la chica rara:}

El relato empieza con la llegada de Andrea a la estación del tren y se acaba con su decisión de partir hacia Madrid para empezar de nuevo una carrera universitaria, y una nueva vida. En

(El siglo XX, el despertar de la narrativa femenina...) Dr. Laila Awadallah 
cuanto al tiempo cronológico de la novela, los sucesos ocurren en un año, mejor dicho, nueve meses o un año escolar. Normalmente un año no es mucho tiempo para una novela de bildungsroman que trata la vida de una protagonista a lo largo de un periodo de tiempo más largo. A pesar de que, en Nada, encontramos una cantidad enorme de sucesos y cambios bruscos en la formación del carácter de Andrea, hasta el punto de poder decir que la chica que salió de la casa de la calle de Aribau, de Barcelona, es totalmente diferente a la adolescente que entró en la misma casa un año antes. Andrea habrá pasado por un proceso de maduración y de búsqueda de su propia identidad.

Andrea, la protagonista-narradora omnipresente, pasa este tiempo en casa de su familia, y esto le ocasiona muchos cambios de carácter y también psicológicos, lo que nos puede llevar a dividir su vida en tres etapas: La primera desde su llegada a Barcelona y sus primeros pasos por una gran ciudad; la segunda habla de su vida universitaria; y la tercera con la muerte de otro familiar, su tío; y, por último, la historia termina con la decisión de la joven de empezar de nuevo en otro lugar elegido por ella. Existen señales que aparecen a lo largo del texto que nos explican algunos rasgos de la vida de Andrea antes de que vaya a vivir en casa de su abuela.

Si relacionamos esta parte de la narración con la vida de Carmen Laforet, observaríamos que sustituye la figura odiosa de su propia madrastra, que según contaba, la maltrataba, por el

(El siglo XX, el despertar de la narrativa femenina...) Dr. Laila Awadallah 
paralelismo con la prima de Andrea, que la cuidaba después de la muerte de sus padres. Sabemos que Andrea es huérfana, igual que Laforet.

En la primera escena de la novela, su autora nos presenta a Andrea, la protagonista. Viaja sola a Barcelona y llega a la capital catalana primeras horas de la madrugada, cargada con una maleta llena de libros. Se la ve arrastrando su pesada maleta, sin rumbo por el horario del tren, ya que sus familiares no le abren la puerta de casa porque llega de madrugada, y no son horas de recibir visitas. Ella describe así esa procesión sin rumbo, cargada con el maletón: "Empecé a seguir -una gota entre la corriente- el rumbo de la masa humana que, cargada de maletas, se volcaba en la salida. Mi equipaje era un maletón muy pesado -porque estaba casi lleno de libros- y lo llevaba yo misma con toda la fuerza de mi juventud y de mi ansiosa expectación"17.

En estas primeras escenas de la novela carecemos de una descripción física de Andrea, sólo podemos dibujar su silueta flaca sin ninguna fisonomía clara. La joven es una de estas chicas que pasan por tu lado sin que te fijes en ella, a diferencia de su amiga Ena, que la autora prefiere presentarla como una chica muy guapa, admirada por casi todos sus colegas de la facultad, aparte de poseer una gran riqueza y buen gusto a la hora de vestirse. Ena representa la otra cara de la moneda de Andrea, diríamos que son la cara y la cruz.

(El siglo XX, el despertar de la narrativa femenina...) Dr. Laila Awadallah 
La emocionalidad de Andrea y su psique en el viaje a Barcelona se puede dividir también en tres etapas principales, igual que el trayecto vital de esta trilogía que estamos describiendo, tanto por edad y madurez, como por evolución del pensamiento y del empoderamiento como mujer en sociedad. La primera de estas etapas emocionales estaba caracterizada por grandes sueños e ilusiones que intentará cumplir escuchando sus propias sensaciones al llegar a Barcelona siendo menor de edad y sola. Recordemos que, en esta época, los jóvenes llegaban a la mayoría de edad a los veintiún años. La segunda etapa emocional se sitúa en la huida. Muchos jóvenes, a lo largo del tiempo, huyen siendo menores de edad pensando que la huida les aportará un bienestar que no tienen en el entorno familiar. Este prototipo es el caso de Andrea, que desea separarse de la relación tensa con su prima Isabel, que la cuidaba tras de quedar huérfana de madre, y busca empezar una nueva vida con el ingreso en la universidad,. Y todo ello adobado con una profunda sensación de miedo, mucho miedo.

Durante una conversación con su tío, Andrea le confesó que en realidad no le gustaba fumar. Comenta que sólo fingía practicar este mal hábito para poder venir a Barcelona. Estas son sus palabras: "Pues no me gusta fumar. En el pueblo lo hacía expresamente para molestar a Isabel, sin ningún otro motivo. Para escandalizar, para que me dejara venir a Barcelona por imposible"18. Laforet no da detalles del periodo anterior a 
Barcelona, de su infancia y adolescencia en Canarias, parece que lo que realmente le interesa describir al detalle es a la joven que sale a buscarse la vida, esa iniciativa que casi siempre se da en los jóvenes con un punto de inmadurez, inseguridad y grandes ganas de aventura, y que les aporta ese optimismo y esa fuerza a pesar de los obstáculos. Esta primera fase está caracterizada por el gran deseo de Andrea de educarse, piensa en la Universidad, en conocer un tema en profundidad. Es la típica chica joven que piensa en los estudios como único camino para salvarse de las tradiciones anticuadas y para ser libre e independiente. Así lo expresa en su texto Ninna Pórarinsdóttir: "Lo que Andrea quiere, como ya se ha mencionado, es tomar sus propias decisiones. No quiere seguir las normas convencionales como casarse, hacerse monja ni escuchar las órdenes de los hombres. Además, quiere educarse, ser económicamente independiente, trabajar, vivir sola y controlar su vida ${ }^{19}$,.

\section{Diferentes tipos femeninos en Nada:}

Las principales protagonistas femeninas en la novela, junto a Andrea, son la abuela, la tía Angustias, Gloria, Ena y su madre. Cada una de ellas desempeñó un papel en la evolución y madurez en el carácter de Andrea. Cabe mencionar que la abuela es la única persona que intenta conservar los principios católicos impuestos por el régimen franquista, pero también es la fuente de ternura y cariño para toda la gente que existe en su entorno

(El siglo XX, el despertar de la narrativa femenina...) Dr. Laila Awadallah 
familiar. Carmen Laforet nos presenta la tía Angustias como persona fuerte, muy conservadora, que se aferra mucho a las tradiciones y a las costumbres, muy fiel a los doctos católicos, y forma una barrera que impide a Andrea disfrutar de su estancia en Barcelona por su estricta vigilancia sobre la muchacha. Esta mujer de hierro, aparentemente, no tarda en derretirse ante nuestros ojos al descubrir que Angustias esconde detrás de su fuerte aspecto y su contundente castidad otra figura de mujer débil, que tuvo una fracasada aventura romántica con su jefe, un hombre casado, don Jerónimo. Por este motivo, decide autocastigarse entrando en un convento para evitar la crítica social.

Angustias es la tía de Andrea, es aquella mujer que al principio quería jugar el papel importantísimo de madre cuando falleció la madre de Andrea. Es decir, realmente lo que hizo Angustias fue asumir el papel de madre sustituta, una madre tiránica y dominadora, y todo ello fue rechazado por Andrea, que hacía todo lo posible por escapar de la vigilancia de la tía (como en el cuento de Blancanieves y los siete enanitos, la madrastra era pérfida y despreciable, o La Cenicienta). Según el criterio de Andrea, Angustias no podía simbolizar ni igualar a su difunta madre. El paralelismo es que tanto la autora como su personaje son huérfanas de madre, y otro personaje femenino en los dos casos quiere usurpar de malas maneras el papel de madre, sin que sepan hacerlo y tiránicamente. Las dos encuentran a madrastras de cuento, en el sentido negativo del término. Porque, en realidad, el

(El siglo XX, el despertar de la narrativa femenina...) Dr. Laila Awadallah 
concepto de madrastra es simplemente la persona que se casa con un hombre con hijos, sin más, no es ni negativo ni positivo. Pero, la tradición literaria ha incorporado aspectos al término de uso popular también e históricos de personajes femeninos que no actúan adecuadamente respecto a los afectos familiares con los hijastros y las hijastras. Esta fijación en Laforet le lleva a explicar el personaje de la madrastra también en su segunda novela La isla y los demonios.

El conflicto generacional se refleja claramente en la relación entre Andrea y su tía Angustias, un personaje rebelde y liberal se choca contra un carácter conservador. La relación tíasobrina pasa por muchos momentos decisivos para ambas, sobre todo en el proceso de formación de Andrea. Angustias deseaba desempeñar el papel de madre sustituta en la vida de su sobrina, un acto que fue rechazado firmemente por la adolescente. Lo que lleva a la tía tomar su decisión de dejar la casa familiar y entrar en el convento, miramos un diálogo entre ambas mujeres que refleja la visión dominada en España durante el periodo de posguerra sobre la mujer y su papel en la sociedad:

Dice Andrea a su tía: “Según tú, una mujer, si no puede casarse, no tiene más remedio que entrar en el convento?” A tal pregunta responde Angustias, la tía: "Pero es verdad que sólo hay dos caminos para la mujer. Dos únicos caminos honrosos... Yo he escogido el mío, y estoy orgullosa de ello. He procedido como una hija de mi familia debía hacer" 20.

(El siglo XX, el despertar de la narrativa femenina...) Dr. Laila Awadallah 
En otro sentido, Gloria se presenta como ejemplo de la degeneración moral resignada y reconvertida por su pecado. Ella representa la figura de anti-héroe del modelo ideal de la mujer franquista de la época que fundamentalmente se identificaba con la esposa y madre, muy dignas. Pero ella, a pesar de ser esposa y madre, sigue intentando seducir a su cuñado, y no deja de mostrar, sin pudor, su bonito cuerpo femenino al desnudo:

"Gloria influye en el desarrollo personal de Andrea porque aprende a no dejar que un hombre gobierne su vida pisoteando su amor propio y golpeando su corazón y su cuerpo. Aprende que, si la sociedad la menospreciaba por atreverse a ser diferente, debería seguir adelante para alcanzar su verdadera realización y por eso Andrea la estima tanto"21.

Digno de mencionar es que tanto Angustias como Gloria forman, incuestionablemente, modelos de víctimas de violencia de género, según las nuevas teorías de la literatura feminista, y las tendencias sociales actuales. La tía Angustias no pudo aguantar la mirada criticona de la sociedad española conservadora, tan sumamente cerrada, que arrebataba a la mujer su derecho a la igualdad de oportunidades en relación al hombre, por lo cual, decide escapar encontrando refugio en el servicio religioso, el mismo comportamiento de las mujeres durante el Antiguo Régimen y la época Medieval hasta hace pocas décadas. El caso de Gloria es el de una mujer que se somete diariamente a los 
malos tratos por parte de su marido, bajo el peso de la penuria y la escasez, ya que no tiene cubiertas las necesidades básicas.

Entre los personajes femeninas más relevantes y de mayor influencia en la formación de Andrea está su amiga Ena y todo su entorno familiar:

"La amistad en el Bildungsroman tiene una gran importancia pues es de ahí que el personaje principal obtiene los consejos o modelos a imitar en su propia vida. En la vida de estas dos jóvenes protagonistas, sus amigas, confidentes y consejeras, tienen el rol de ayudar a formar su carácter y a enfrentarlas con la dura realidad dando esperanza. Ellas maduran en sus relaciones y se quedan con lo mejor de cada amistad en su corazón y memoria"22.

\section{Ambientación de la novela:}

Tal como hemos mencionado en apartados anteriores, en la novela Nada el tema central es el conflicto generacional. La protagonista no puede encontrar canales de entendimiento con ninguna de las personas de su familia, a pesar de que conviven en la casa familiar, motivo esencial por el cual se duplicó su aislamiento y su sentido de soledad. Estos sentimientos la llevaron a buscar el sosiego que soñaba fuera de casa, sumergiéndose en relaciones y amistades con personas ajenas de su entorno familiar. Estamos ante un modelo de una mujer diferente, una mujer nueva, y rara, simplemente una jovencita

(El siglo XX, el despertar de la narrativa femenina...) Dr. Laila Awadallah 
aparentemente rebelde. El contexto de España de la posguerra no deja mucho margen para esos tiernos vuelos de los jóvenes, con un ambiente opresivo, cerrado y conservador, el único papel aceptado para la mujer era formar una familia, cosa que de momento no está en los planes de Andrea. Tampoco era normal ver a una chica andando sola por las calles de la ciudad sea de día o de noche. Mucho menos se veía como normal que las chicas estudiaran en la Universidad, cosa que incluso impedía a muchas que pudieran llegar a casarse. Contrariamente a lo que actualmente sucede, una mujer culta, estudiosa y bien formada era motivo de rechazo social, se la veía con miedo por 'saber demasiado', y sobre todo por los hombres, que pensaban que la mujer debía tener unas cualidades que no sobrepasaran las de su marido. Por ejemplo, en temas tan tontos como que debía tener algunos años menos que su marido, ser igual o más baja de estatura que él, dispuesta a obedecer las órdenes que él le impusiera con el criterio de que tanto intelectualmente como en experiencia eran más aptos que ellas para tomar decisiones. La mujer pasaba de estar a las órdenes del padre de familia a las del marido una vez casada, (o los hermanos si era solterona), así que las mujeres universitarias o con estudios les daban una especie de miedo y de risa, con lo cual, hasta era motivo de burla, y a veces recibían tratos grotescos y despectivos. Con estos datos históricos del contexto, nos damos cuenta de que estamos ante el relato de una mujer con ideas vanguardistas y feministas, avanzada a su 
época y luchadora. Un relato que abre camino a otras mujeres y otros hombres que no se conforman con esta época oscura en la Historia reciente de España, y que casi se les ve yendo a contracorriente. Pero, claro, el tiempo no pasa sin dejar su huella. El tiempo les ha dado la razón y los jóvenes tienen ahora muchas oportunidades para disfrutar de sus vidas, de su inteligencia y de su libertad.

Todos estos factores contribuyeron a ver en Andrea un ejemplo claro de personaje principal caracterizado en una novela típica del bildungsroman femenino. Así explica Myriam del Río algunos aspectos de la personalidad de Andrea que ya han quedado claros: "Andrea lucha por integrarse sin renunciar a ella misma. La novela constituye un bildungsroman de búsqueda de identidad donde la protagonista se enfrenta a la incomunicación, la falta de espacio propio y la falta de conexión con los demás. Sus esfuerzos parecen casi siempre en vano."23.

\section{La dualidad casa-hogar:}

Así, los sucesos de esta novela transcurren entre dos mundos contrarios y opuestos. No obstante, la casa de la calle de Aribau desempeña un rol importantísimo en toda la historia que narra esta autora. Aparte de ser la residencia familiar, representa un microcosmos de la sociedad española simbolizada en una sola ciudad, Barcelona, una ciudad con una importancia caudal dentro del Estado español, en la que la mayoría de las mujeres trabajan en casa y en fábricas textiles. Sin embargo, es imprescindible 
destacar el impacto que aporta la casa familiar de Barcelona, en la que está durante un año, en la formación del carácter de Andrea. "Andrea penetra en ella con la inocencia e ingenuidad románticas de una adolescente de 18 años y se encuentra con un mundo enmohecido, umbrío. Es más: el desarrollo y maduración del personaje de Andrea sólo puede entenderse si se ve en relación con la casa, con sus habitantes -que viven encerrados en ella. ${ }^{24 " . ~ E s ~ c i e r t o, ~ e l ~ m a l ~ i m p a c t o ~ q u e ~ s e ~ l l e v o ́ ~ d e ~ l a ~ c a s a ~ d e ~ s u s ~}$ paredes era palpable. Nos describe una casa con la pintura caída, los espejos rotos, y los muebles anticuados, a pesar de que forma parte de una familia burguesa con poder adquisitivo superior a muchas familias que incluso pasan hambre y necesidad vital. Por otro lado, la decoración de la casa no es lo más impactante sino la forma de relación de sus habitantes: la agresividad que movía los comportamientos entre ellos y, incluso, con el mundo exterior.

La casa de la calle de Aribau no es el hogar y el refugio para los miembros de la familia, tal como entendemos hoy la protección de la familia respecto de todos sus miembros, más bien al revés, la casa de los abuelos de Andrea se muestra en el texto como un lugar extravertido, hasta peligroso para tener una cierta calma y estabilidad. Es más, todos sus habitantes sólo se sienten seguros fuera de esas paredes. La casa es la muestra de su opresión física y personal. Podemos decir que la casa en Nada no sólo representa el espacio donde transcurren una gran parte de las acciones de la novela, sino que se ofrece en la novela como un 
personaje principal, como con vida propia. Y esta casa, por supuesto, defrauda las expectativas que Andrea tenía al llegar a Barcelona y alojarse en la casa de calle Aribau, que es una calle del centro de la ciudad, donde viven familias de un alto nivel económico y social, incluso actualmente, es una de las zonas más caras de la ciudad Condal, en Cataluña. "El apartamento rápidamente se vuelve un infierno para Andrea ya que sufre hambre, violencia física y psicológica a mano de sus parientes y una represión total por parte de su tía Angustias ${ }^{25}$

Nuestra deducción respecto a este espacio íntimo de la casa radica en compararlo con el paraíso perdido para la joven. El sueño y la ideación de Andrea con relación al hogar que le esperaría al llegar a Barcelona se convirtieron en la peor pesadilla que tuvo en toda su vida. Incluso a pesar de que guarda los recuerdos de su vida allí con sus padres antes de que muriera la madre, antes de que se sintiera realmente sola. Apuntar también que la figura de la madre de su amiga Ena se asemeja a la de su madre, y, apuntando este aspecto autobiográfico de la escritora (aunque ella quisiera negarlo), también se asemeja a la madre de la misma Carmen Laforet. La casa, el espacio eminentemente materno, es otro paraíso perdido para estas dos mujeres, Laforet, crea de su imaginación unos personajes que sufren, igual que la propia autora. La idea de pérdida es muy fuerte en la obra, tanto en lo que describe el espacio como en lo que afecta a los personajes. Una pérdida que la autora por mucho que la elabora 
en sus textos, no logra superar. No fue fácil este periodo para la mayoría de mujeres, fueran ricas o pobres. Sin ir más lejos, la célebre autora Emilia Pardo Bazán dijo con sus palabras en una entrevista que mejor le hubiera ido si en vez de llamarse Emilia, en mi carnet de identidad pusiera Emilio. Y está claro, este pensamiento estaba motivado porque la identidad de la mujer estaba supeditada a la del varón, fuese su marido, su hermano o su padre, o abuelo. Todos ellos disfrutaban de autoridad sobre una mujer, así que tenían poca oportunidad de movimiento debido a ese techo de cristal, por utilizar una expresión muy actual para denominar de forma suave lo que se vivía o incluso se vive en algunos lugares del Planeta.

Si nos situamos en el espacio exterior, en el ambiente de otros espacios exteriores donde se mueve Andrea, vemos que respira y es donde se siente mucho más libre y segura que en casa. Lugares como la universidad, la casa de su amiga Ena, la casa del amante, y las calles de Barcelona, por donde suele pasear y vagabundear para sentirse libre y fomentando su interés por el conocimiento y la novedad, son espacios abiertos, son espacios creativos por decirlo de alguna manera.

Para poner punto y final a este apartado del análisis de la novela de Carmen, hay que señalar que el final de su texto viene para poner punto y aparte en la vida de la heroína de la historia, la joven Andrea. No nos parece un final brusco, al contrario, es el inicio de otra vida, una fase llena de más ilusiones. Ilusiones igual

(El siglo XX, el despertar de la narrativa femenina...) Dr. Laila Awadallah 
de fuertes o más que a su llegada a Barcelona. Nos parece un final perfecto, donde el viaje toma cuerpo y forma parte del crecimiento de la joven, donde puede vivir experiencias y comienza una nueva vida en carretera con el coche del padre de su íntima amiga, para buscar de nuevo en otra ciudad, la capital, y marchar con otro rumbo y otro modo de vida. Si buscamos una moraleja en este final, se nos ocurre la frase célebre de "la vida sigue”. Y la vida sigue para la joven Andrea, la experiencia es la base de la ciencia de la vida. Y hay que vivirla con todas sus consecuencias. Laforet lo explica claramente con palabras sencillas de la protagonista:

"Antes de entrar en el auto alcé los ojos hacia la casa donde había vivido un año. Los primeros rayos del sol chocaban contra sus ventanas. Unos momentos después, la calle de Aribau y Barcelona entera quedaban detrás de mí" 26 .

\section{La isla y los demonios, segunda novela de Laforet:}

En febrero de 1952, Carmen Laforet publica su segunda novela, La isla y los demonios, ambientada en la isla de las Palmas de Gran Canaria, donde la autora pasó casi toda su infancia y una buena parte de su adolescencia. En esta obra narra la historia de la joven Marta, hermana gemela de Andrea, protagonista de su primera novela Nada. Por ello, mantenemos esta doble lectura de las dos primeras novelas de Laforet, Nada,

(El siglo XX, el despertar de la narrativa femenina...) Dr. Laila Awadallah 
como inicio de la vida, y La isla y los demonios, como continuación y desarrollo de las vidas de sus personajes principales. El título es sumamente descriptivo, lo dice todo, complementa y encuadra lo que viene dado por el texto de La isla y sus demonios. Así lo muestra la cita siguiente respecto a la obra que pasamos a describir ahora: "El título corresponde a las dos grandes fuerzas que guían al narrador: el paisaje de la Gran Canaria, maravillosamente presentado en varios momentos del relato, y la trama de pasiones humanas a las cuales la autora llama 'demonios'”27. Nuestra escritora emprendió su nueva obra obsesionada con la idea de recoger la belleza de Gran Canaria tal como la deslumbró en el transcurso de su adolescencia. Para hacerlo, eligió a una joven adolescente de dieciséis años y desfiló y apuntó las desilusiones que acompañan su desarrollo personal, emocional y sentimental. Un desarrollo muy marcado por acontecimientos críticos en Europa, por momentos de mucho miedo social y peligrosidad. De ahí el gran valor histórico de estas dos obras maestras de la historia de la Literatura Universal. Desde el punto de vista de la juventud, que en principio le queda toda una vida por delante, hemos llegado a la actualidad, pensando en este trabajo de análisis de esta obra de mediados del siglo $\mathrm{XX}$, que los jóvenes de antes son una generación que está a punto de desaparecer por edad, son personas ya de la tercera edad, que en su día pudieron tener esas ilusiones, unas veces frustradas y otras no. Esta generación ha visto el avance en la psique de los jóvenes 
de ahora, que tienen todas las oportunidades del mundo para convertirse en grandes personas, libres y colaborativas, en base a una enseñanza correcta y a unas relaciones familiares y sociales igualitarias.

Como hemos señalado anteriormente, es la segunda obra de Carmen Laforet; publicada a los treinta y dos años de edad, ya con una madurez adquirida con la gran acogida de su primera novela de juventud unos años antes, y es una edición muy esperada en los círculos de críticos y escritores, en los sectores culturales de la época. Tras el gran éxito que obtuvo Nada a ambos niveles, del lado del público y de los críticos, parece una paradoja querer enmarcar las dos obras en un solo contexto, este artículo crítico, ya que la obra que motiva el presente trabajo es la primera de la autora, con la que aporta algo nuevo a la historia de la Literatura. ¿No hay suficiente material en Nada para ser analizado? ¿O quizás, es posible que, ésta marcada complementariedad de ambas obras haga que nuestro estudio no esté completo si no las abordamos en conjunto? "Pero ya en La isla y los demonios se siente desde la primera página la objetividad del relato, escrito en tercera persona. Marta Camino, una Andrea más adolescente, más inexperta y absorta, pero igualmente romántica, es ya un personaje visto desde fuera, desde la retina de un novelista, y aunque el personaje deje traslucir algún rasgo autobiográfico, es un personaje ${ }^{28, "}$

(El siglo XX, el despertar de la narrativa femenina...) Dr. Laila Awadallah 
El título simbólico de la obra, La isla y los demonios: las Palmas de Gran Canarias es la isla, donde vemos los trazos autobiográficos de la autora; y los demonios son las pasiones que atormentan las relaciones de los personajes que participan en esta historia. El tiempo exterior, el contexto ambientado entre 1938 y 1939 en España, en pleno final de la Guerra Civil. A diferencia de Nada, el narrador en esa obra no es la misma protagonista, sino una tercera persona omnipresente. A lo mejor Carmen Laforet ha optado por cambiar el narrador en su segunda obra para escapar de las acusaciones que la perseguían después de publicar Nada, de ser una obra autobiográfica. Así, otra de las coincidencias radica en cómo las dos novelas describen el ambiente familiar y los continuos conflictos entre los miembros de la misma familia.

\section{Puntos de concordancia:}

La historia gira alrededor de Marta Camino, una adolescente de Gran Canaria que espera con ansia la llegada de unos familiares que vienen desde Madrid para refugiarse en casa de sus parientes a causa de la guerra de España. Los personajes que aparecen en la novela están mejor construidos psicológicamente, sin embargo, están llenos de sentimientos negativos y hostilidad unos contra los otros. Aquí se muestra el contexto de la protagonista:

"Con su llegada empieza la aventura de Marta, que poco a poco va madurando y crece como persona en un

(El siglo XX, el despertar de la narrativa femenina...) Dr. Laila Awadallah 
entorno hostil, dado que sus familiares acaban siendo exactamente igual que su hermano por mucha alma "libertina" que tengan no se interesan por una muchacha adolescente con ansias de escapar y conocer mundo" 29 .

\section{Marta Caminos, la adolescente Andrea:}

Desde nuestro punto de vista, el personaje que más interesa aquí es Marta Caminos, la joven protagonista de la novela, por formar con Andrea un ciclo continuo que empieza por La isla y los demonios y continúa en Nada, en este orden cronológico de la vida fantástica de este personaje con dos nombres diferentes, pero bajo el mismo encuadre tanto psicológico como de contexto. Es decir, la historia comienza al revés, la adolescente Marta, de joven será la joven Andrea. Marta es menor que Andrea y la describe justo antes de marcharse a Barcelona. En ese momento de la 'huida' de casa ya es una joven con decisiones propias. Mientras que Marta aún es una muchacha vulnerable y llena de imaginación, aficionada a la música y a la pintura, que anhela la llegada de sus parientes pensando que podrían comprender mejor su lado más fantasioso.... Una ilusión que pronto la llevará a la frustración total. "A lo largo del libro descubre lo que es la libertad y la prisión, el sentirse como una niña y a la vez parecer la única adulta, saberlo todo y a la vez no saber nada. Es la personificación de una adolescente confundida que intenta hacer

(El siglo XX, el despertar de la narrativa femenina...) Dr. Laila Awadallah 
las cosas bien, por mucho que el mundo se lo impida y todo esté en su contra" 30 .

Los temas dominantes son la frustración amorosa, los conflictos familiares, la rebeldía y la búsqueda de la identidad. Son casi los mismos conceptos que dominan en su primera obra, Nada. Lo más sorprendente es que el final de las dos obras también es muy parecido. En La isla y los demonios, Marta decide huir de todo este ambiente para empezar de nuevo en la península ibérica, lo mismo que hace Andrea en Nada, la idea de viaje, de cambio, recorrido, de huida, el tránsito a la madurez se hace a través del viaje interior y exterior. Andrea es quien decide dejar la casa de la calle de Aribau rumbo hacia Madrid para empezar una nueva vida junto a su íntima amiga Ena. El viaje de la amistad es tan sumamente importante para los adolescentes y los jóvenes en general, que queda claramente plasmado este sentimiento en las dos novelas:

"Rodeada de esas pasiones, de esos demonios, Marta Camino escoge intuitivamente -pues toda ella es pura intuición, como es la adolescencia- la única vía de salvación, frustrado el amor imposible con Pablo, el pintor. Esta vía es la de la huida. Marta huye de su isla, la isla dorada, hacia la península, donde quizá encuentra otros demonios, los demonios de la calle Aribau, si es que nos complace imaginar a Andrea como a una continuación de la adolescente Marta"31.

(El siglo XX, el despertar de la narrativa femenina...) Dr. Laila Awadallah 
Por otro lado, la protagonista, Marta Camino, es una adolescente de dieciséis años, que se encuentra en una continua búsqueda de su identidad, soñando llegar a etapa de madurez, un intento incompleto. También, Marta vive rodeada de un entorno familiar disfuncional, como es el caso de Andrea en la casa de la calle de Aribau. El contexto de Marta: una madre casi trastornada mentalmente, una cuñada colérica, y un hermano autoritario; junto a los otros parientes, que esperaba su llegada con mucho entusiasmo, al final descubrió que son igual de nocivos.

Tanto Marta en La isla y los demonios, como Andrea en Nada están rodeadas de un mundo lleno de insinuaciones negativas, un ambiente duro, hostil y agrio. También las dos obras comparten una gran variedad de los caracteres femeninos y una riqueza psicológica en la descripción de las mujeres que participan en ambas novelas, sea Andrea o Marta, en la búsqueda para poder encontrar su propio rumbo. Las dos deciden en un momento determinado renunciar a su mundo opresivo, dejar atrás su pasado para buscar una nueva vida en otro sitio, en otra ciudad. Las dos chicas comparten la misma realidad, escapar del ámbito familiar para ir a vivir en la capital, Madrid, Barcelona..., formando una cierta atracción para ambas chicas, ya que tienen la idea de liberación de todas las ataduras sociales y familiares. " $\mathrm{Su}$ figurilla de adolescente se recortó un momento a contraluz, con la falda oscura y el jersey claro, de mangas cortas. El aliento del mar, muy ligero aquel día, le empujó los cabellos, que brillaban

(El siglo XX, el despertar de la narrativa femenina...) Dr. Laila Awadallah 
cortos, pajizos. Se puso la mano sobre los ojos, y toda su cara parecía anhelante y emocionada"32.

\section{Conclusión:}

El título de la obra Nada refleja la desilusión de la protagonista Andrea al final de la obra cuando en realidad no ha conseguido realizar sus sueños e ilusiones. La autora de Nada nos transmite las duras condiciones económicas y morales de los años cuarenta. Así como el título de la otra novela, La isla y los demonios indica unos sentimientos negativos sobre la soledad y los miedos, la locura y el enfrentamiento, sin ir más lejos, los dos hermanos se odian y se quieren, pero se enfrentan a muerte, igual que en esta guerra fratricida que se describe o apunta en el contexto de las dos novelas, traiciones, denuncias, locura por las consecuencias de los desastres.

Como la negación en el título de la primera novela de la joven Laforet, una negación que atribuye a que fueron robados con la victoria del general Franco y su Falange. Robaron la tranquilidad y el pan, la concordia, la fraternidad... El régimen franquista relegó a la mujer española al mundo de la familia y la maternidad, y el trabajo duro, pero con la boca callada, ya que volvió a ser ilegal el divorcio, un avance conseguido en la República. Aparece una legislación discriminatoria que les niega la libertad y la igualdad, igual como lo que fue establecido durante la época feudal, que incluso el señor del feudo tenía 
derecho de pernada ante los nuevos matrimonios. El pobre pasó a ser más pobre. Y la mujer pasó a ser más esclava.

El descubrimiento del bildungsroman en Carmen Laforet con sus dos textos, dando forma a un grito por parte de la mujer, un grito que protesta por la pérdida de todos los derechos logrados a manos de la Segunda República, la convierten como escritora y persona en una señora que se atreve a todo, o casi todo, por desdoblar esas memorias de un tiempo histórico inolvidable por sus horrores, por su falta y por su negación.

Tanto Andrea en Nada como Marta en La isla y los demonios aprenden de salir de los límites preestablecidos por los hombres de su entorno familiar y por la sociedad española. Logran retomar su identidad al alejarse de los espacios opresivos en los que viven. Logran construirse a sí mismas, convertirse en adultas en medio de una sociedad dominada por hombres. Sus vidas son transformadas como fruto de mucho esfuerzo, largas caminatas por la ciudad, amistades, relaciones amorosas, y mucha hambre.

A modo de conclusión, estamos en las dos novelas ante la lucha de una adolescente por abrirse paso en la vida, por forjarse un lugar en el mundo de los adultos, por no limitarse a recibir la existencia que se le destina, sino elegir por sí misma, en medio de los obstáculos que tal actitud representa, en medio de los problemas de quienes la rodean. Digno de mencionar es que Marta en La isla de los demonios tiene una descripción física y

(El siglo XX, el despertar de la narrativa femenina...) Dr. Laila Awadallah 
psicológica, mientras Andrea carece de tales detalles, como si a Carmen Laforet le bastara con la citada en 'la isla' para adivinar el aspecto de Andrea, o como si estuviera completando lo que faltaba en Andrea.

Quizá los parientes de las dos chicas no forman los mismos enlaces de parentesco, sin embargo, representan un entorno familiar sofocante y oprimente sobre ambas chicas que al final las llevó a buscar su identidad en otro sitio tan lejos de su dominio. Así como destacar finalmente los temas preferidos y concurrentes en la novelística de Carmen Laforet, como la pérdida de identidad, la migración, la rebeldía, la crítica social están muy presentes y discutidos en ambas novelas.

Concluimos que, si Nada se puede considerar como la primera novela de estilo bildungsroman femenino en el siglo XX, la obra tiene que esperar unos siete años hasta que saliera a la luz La isla y los demonios para llenarnos las lagunas y desvelar las ambigüedades sobre el personaje de Andrea. Nos pone al descubierto la parte desconocida de su carácter. A pesar de una continua negación por parte de Carmen Laforet sobre que sus obran fueran autobiográficas, es tan obvio, que queda clara la decisiva influencia de sus años de adolescencia en su formación y su producción literaria.

Las dos jovencitas aparecen ante los ojos del lector como si fueran una sola persona con dos años de diferencia, y como si las dos obras fueran una sola novela con dos partes, editadas en una

(El siglo XX, el despertar de la narrativa femenina...) Dr. Laila Awadallah 
dirección contrarreloj. Marta es un personaje más joven que Andrea, tal como hemos mencionado, y de ahí el estilo bildungsroman, en el cual asistimos a la formación del carácter de sus personajes a lo largo de un tiempo determinado, en su crecimiento como persona.

Al finalizar La isla y los demonios, Marta abandona la isla y reaparece en Barcelona bajo el nombre de Andrea. Todo lo que soñaba Marta es llevar los libros de su padre en una maleta y dejar la isla, y. La primera escena de Nada muestra la llegada de Andrea a la estación, cargada con una gran maleta llena de libros. Aparte de lo que simbolizan los libros, que nos muestran un carácter de chica culta y buena lectora, esta escena refleja también cuánto de idénticas son en sus gustos y apetencias, en sus deseos.

(El siglo XX, el despertar de la narrativa femenina...) Dr. Laila Awadallah 
${ }^{1}$ Bildungsroman es un término alemán que significa 'novela de formación' o también se transcribe como 'novela de educación', también como 'historias de mayoría de edad'. Normalmente tratan sobre el trayecto de maduración de uno o varios personajes. Este concepto fue acuñado en 1819 por el filólogo Johann Carl Simon Morgenstern.

2 carmenlaforet.com, la página principal de Carmen Laforet, [consultada el 14 de enero 2020].

${ }^{3}$ Ibíd.

${ }^{4}$ Teresa AMIGUET, “Carmen Laforet, la escritora grafofóbica”, en La Vanguardia, 06-01-2015.

5 https://www.escritores.org/biografias/66-carmen-laforet-diaz, [consultada el 6 de diciembre de 2019].

6 Caroll BUITRAGO-LONG, Mujeres en proceso de construcción, Illinois, Department of Foreign Languages and Literatures, Southern Illinois University Carbondale, 2010, pág. 2.

${ }^{7}$ María del Mar LÓPEZ VILADRICH, La adolescente en la narrativa femenina de posguerra: Carmen Laforet y Ana María Matute, Tesina de máster inédita, Madrid, UCM, 2013.

${ }^{8}$ Caroll BUITRAGO-LONG, ob. cit., pág. 6.

${ }^{9}$ Carmen LÓPEZ HERNÁNDEZ, Nada o la verdad no sospechada, Almería, 1996, pág. 64, en www.researchgate.net.

${ }^{10}$ Francisco Juan Quevedo García, "Una perspectiva melodramática en La isla y los demonios, de Carmen Laforet”, en Anuario de Estudios Atlánticos, Gran Canaria, 2014, pág. 707.

11 Tremendismo: es una corriente estética que abarca el ámbito literario, cultural y artístico en el cual sus autores destacan la vertiente más cruda y rotunda de la realidad, incluso exagerando algunos aspectos que aportan mayor impacto para dar cuenta de los extremos que se daban durante todo el siglo XX. Esta técnica narrativa se centra en España sobre los años 1940. Se plasma tanto en poesía y novela como en teatro. Surge como manifestación de la renovación y resurgimiento de la novela, y a

(El siglo XX, el despertar de la narrativa femenina...) Dr. Laila Awadallah 
este movimiento se apunta toda una generación que, por su estilo marcado por la cruda posguerra, se agruparan bajo el término tremendismo.

12 Laforet es calificada como una novelista neorrealista en el estudio que hace María Dolores de Asís Garrote, en su libro: Última hora de la novela en España, Madrid, Ediciones Pirámide, 1996.

${ }^{13}$ Anthena ALCHAZIDU, Las raíces del tremendismo español, edita Studia Minora Facultatis Philosophicae Universitatis Brunensis, L 26, 2005, página 28.

14 Miguel Ángel GARCÍA GUERRA, Nada, de Carmen Laforet, magarciaguerra.com/2012/12/nada-de-carmen-laforet, [Consultada el 12-09-2019].

${ }^{15}$ Carmen LAFORET, ob. cit., pág. 99.

16 ZAVIEZO, Gabriela, "Vergüenza y confidencias: estrategias para la construcción del sujeto en Nada de Carmen Laforet”, Divergencias. Revista de estudios lingüísticos y literarios, vol. 11, núm. 2, Arizona, invierno 2013, pág. 38.

${ }^{17}$ Carmen LAFORET, Nada, 19a ed., , Barcelona, Ediciones Destino, 1994, pág. 11.

${ }^{18}$ Ibíd., pág. 39

19 Ninna PÓRARINSDÓTTIR, "El trasfondo socio-histórico en Nada de Carmen Laforet", en La situación de la mujer en España durante la Segunda República y el franquismo, Sigillum Universitatis Islandiae, Spænska, febrero 2016, pág. 19.

${ }^{20}$ Carmen LAFORET, ob. cit. pág. 101.

${ }^{21}$ Caroll BUITRAGO-LONG, Ob. cit., pág. 25.

22 Ibíd, pág. 26.

23 Myriam DEL RÍO HERNÁNDEZ, "Reflexiones sobre una nueva identidad femenina: reencuentro con Nada de Carmen Laforet”, Sídney, en Voces Hispanas, Revista de Consejería de Educación en Australia y Nueva Zelanda, número 10, 2013, pág. 27.

${ }^{24}$ Carmen LÓPEZ HERNÁNDEZ, ob. cit., pág. 65.

${ }^{25}$ Gabriela ZAVIEZO, "Vergüenza y confidencias: estrategias para la construcción del sujeto en Nada de Carmen Laforet”, Arizona, Divergencias. Revista de estudios lingüísticos y literarios, vol. 11, núm. 2, invierno 2013, pág. 37.

${ }^{26}$ LAFORET, Carmen, ob. cit., pág. 295.

(El siglo XX, el despertar de la narrativa femenina...) Dr. Laila Awadallah 
27 QUINTANA TEJERA, Luis, "El narrador en La isla y los demonios", Revista latinoamericana de ensayo, año XXIII, Santiago de Chile, 20/05/2004. http://critica.cl/literatura.

28 José Luis CANO, "Carmen Laforet: La isla y los demonios", Madrid, Ínsula. Revista de Letras y Ciencias humanas, número 82, 15/V/1952.

29 Gloria STONEM, "Carmen Laforet: La isla y los demonios", Blog: https://adoptaunaautorablog, wordpress.com/2017/05/29.

${ }^{30}$ Ibíd.

${ }^{31}$ Ibíd.

${ }^{32}$ LAFORET, Carmen, La isla y los demonios, $6^{\mathrm{a}}$ ed., Ediciones Destino, Barcelona, 1991, pág. 3

(El siglo XX, el despertar de la narrativa femenina...) Dr. Laila Awadallah 


\section{BIBLIOGRAFÍA}

\section{1) LIBROS:}

- BIRUTÉ CIPLIJAUSKAITÉ, “La novela femenina contemporánea (1970-1985), Hacia una tipología de la narración en primera persona", en Revista Anthropos, Barcelona, 1988.

- CEREZALES, Agustín, Carmen Laforet, Ministerio de Cultura, Dirección General de Promoción del libro y cinematografía, Madrid, 1982.

- FREIXAS, Laura, La mujer y la literatura: escritoras, público y crítica en la España actual, Barcelona, Editorial Destino, 2000.

- GAITE, Carmen Martín, Desde la ventana, enfoque femenino de la literatura española, Madrid, Espasa-Calpe, colección Austral, 1993.

- GARCÍA LÓPEZ, José, Historia de la literatura española, $19^{a}$ ed., Barcelona, editorial Vicens-Vives, 1980.

- LAFORET, Carmen, Nada, Barcelona, 19ª ed., Ediciones Destino, 1994.

, La isla y los demonios, $6^{\mathrm{a}}$ ed. Barcelona, Ediciones Destino, 1991.

- QUEVEDO GARCÍA, Francisco Juan, "Una perspectiva melodramática en La isla y los demonios, de Carmen 
Laforet”, Gran Canaria, Anuario de Estudios Atlánticos, 2014.

- RICO, Francisco, Historia y Critica de la Literatura española, Época contemporánea 1929-1980, Barcelona, Crítica, tomo VIII, 1980.

- SANZ VILlanUEVA, S., Historia de la novela social española, Madrid, Alhambra, 1986.

- VALBUENA PRAT, Ángel, Historia de la Literatura española, $8^{a}$ ed., Barcelona, edición ampliada por Antonio Prieto y Gustavo Gili, tomo IV, 1983.

- W. PEREZ, Janet, Novelistas femeninas de la postguerra española, Madrid, José Porrúa Turanzas, 1983.

\section{2) WEBIOGRAFIA:}

\section{A)Archivos PDF:}

- BUITRAGO-LONG, Caroll, Mujeres en proceso de construcción, Illinois, Department of Foreign Languages and Literatures, Southern Illinois University Carbondale, 2010.

- CANO, José Luis, Carmen Laforet y la isla y los demonios.

- JORGE de SANDE, María del Mar, Apuntes sobre la novela española femenina de posguerra, Area and Culture Studies Vol.70, 2005.

- LÓPEZ VILADRICH, María del Mar, La adolescente en la narrativa femenina de posguerra: Carmen Laforet y Ana

(El siglo XX, el despertar de la narrativa femenina...) Dr. Laila Awadallah 
María Matute, Tesina de máster inédita, Madrid, UCM, 2013.

- PARDAVILLA, Almudena Martín, La recepción crítica de "Nada" de Carmen Laforet, Instituto de Investigación Feminista, Universidad Complutense de Madrid, 2011.

- QUEVEDO, Francisco J., Una perspectiva melodramática en "La Isla y los demonios" de Carmen Laforet, Anuario de Estudios Atlánticos, Las Palmas de Gran Canaria, 2014, núm. 60, pp. 699-720.

- VALDILLO BUENFIL, Carlos Javier, El bilduingsroman en las narradoras españolas de posguerra: 1940-1960, Madrid, Facultad de Filosofía y Letras, Universidad Autónoma de Madrid, tesis doctoral inédita, 2012.

\section{B) Páginas Web:}

- https// adoptaunaautora.wordpress.com PÓRARINSDÓTTIR, Ninna, El trasfondo socio-histórico en "Nada" de Carmen Laforet, La situación de la mujer en España durante la Segunda República y el franquismo, Sigillum Universitatis Islandiae, Spænska, 2016.

- http:// anuariosatlanticos.casadecolon.com QUEVEDO, Francisco J., Una perspectiva melodramática en "La isla y los demonios" de Carmen Laforet.

- https://critica.cl/ literatura 
QUINTANA TEJERA, Luis, El narrador en la isla y los demonios de Carmen Laforet, fecha de publicación: 20/05/2004, fecha de consulta:...

- https://digilib.phil.muni.cz/handle/

ALCHAZIDU, Athena, Las nuevas voces femeninas en la narrativa española de la segunda mitad del siglo XX, Sborník prací Filozofické fakulty brněnské univerzity. Řada L, romanistická. 2001, vol. 50, iss. L22, pp. [31]-43, en fecha de consulta:.......

- https://Divergencias.arizona.edu/sites/divergencias.

ZAVIEZO, Gabriela, Vergüenza y confidencias: estrategias para la construcción del sujeto en "Nada" de Carmen Laforet. Revista de estudios lingüísticos y literarios, vol. 11, núm. 2, invierno 2013, pág. 37-49.

- www.educacionyfp.gob.es/nuevazelanda.

HERNÁNDEZ, Miriam del Río, Reflexiones sobre una nueva identidad femenina: reencuentro con "Nada" de Carmen Laforet, Voces Hispanas, Revista de Consejería de Educación en Australia y Nueva Zelanda, Sídney, págs. 2731.

- http://lasquimeras.blogspot.com

ARROYO, Manuel Gallego, La isla y los demonios, Carmen Laforet, narrar catedrales de vida interior, Las mil Quimeras, 2011 (22), noviembre (1).

(El siglo XX, el despertar de la narrativa femenina...) Dr. Laila Awadallah 
- http://magarciaguerra.com/2012/12/nada-de-carmen-laforet.

Una lectura feminista de Nada, primera novela de Carmen Laforet, Lucialeelibrossite.wordpress.com. Fecha de consulta

- http://magarciaguerra.com/2012/12/nada-de-carmen-laforet. GARCÍA GUERRA, Miguel Ángel, Nada, de Carmen Laforet, Fecha de consulta: 12-09-2019.

- $\quad$ Www.researchgate.net.

HERNÁNDEZ, Carmen López, Nada o la verdad no sospechada, Almería, España.

- STONEM, Gloria, Carmen Laforet: La isla y los demonios, fecha de consulta:

- WALKOWIAK, Marzena, María, Los ensayos de Carmen Martín Gaite Laura Freixas, Lucía Etxebarría y la posmodernidad española. Actas XVI Congreso AIH, McMaster University, Candá.

(El siglo XX, el despertar de la narrativa femenina...) Dr. Laila Awadallah 


\section{ملخص}

البحث بعنوان "القرن العشرون، بزوغ الفن الروائى النسائى، الرواية التركيبية فى

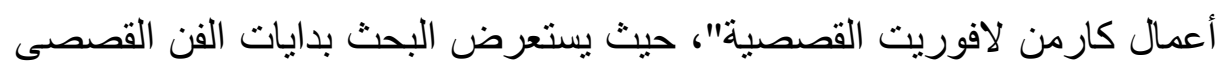
النسائى فى أسبانيا خلال القرن العشرين وأهم رموزه ثم يعرج على كارمن لافوريت ، رائدة الأدب النسائى الأسبانى فى النصف الثانى من القرن العشرين. يتناول البحث الرواية التركيبية buildungsroman فى روايات الأديبة كارمن لافوريت والتى استخدمت هذه التقنية من الرواية التركيبية ليس على مدار عمل

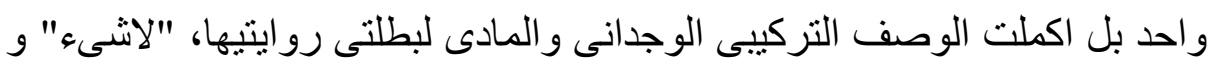
"الجزيرة والثياطين"، وكأننا نقرأ رواية واحدة من جزعين بالرغم من الفارق الزمنى واختلاف تفاصيل الروايتين جملة وتفصيلا. خلص البحث الى أن القراءة

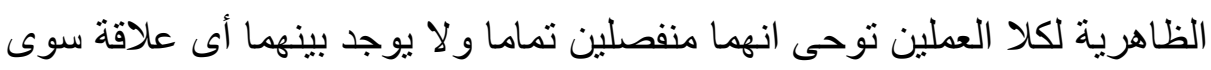
انهما ينتسبان لنفس المؤلف، ولكن القراعة المتعمقة للرو ايتين أظهرت التماثل بين بطلتى الروايتين وظروف حياتهما المعيشية بالرغم من التسلسل المقلوب للعملين بمعنى ان الرواية الثانية فى الكتابة والطبع و الطرح فى الأسواق هى التى تنتاول

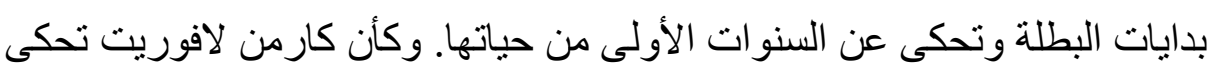
لنا فى عملها بالثانى ماغفلت عنه من تفاصيل فى حياة بطلة عملها الأول. الكلمات المفتاحية: كارمن لافوريت، القرن العشرون، الفن الروائى النسائى،

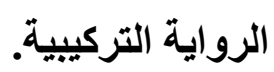

(El siglo XX, el despertar de la narrativa femenina...) Dr. Laila Awadallah 